\title{
Recalling pseudo-psychic demonstrations ${ }^{1}$
}

\author{
Dr Richard Wiseman \\ University of Hertfordshire \\ College Lane \\ Hatfield \\ Herts. \\ AL10 9AB \\ Professor Robert L. Morris \\ Department of Psychology \\ University of Edinburgh \\ 7 George Square \\ Edinburgh \\ EH8 9JZ
}

\footnotetext{
${ }^{1}$ The authors would like to thank Deborah Delanoy, Sybo Schouten and two anonymous referees for providing helpful feedback on earlier drafts of this paper. Our thanks also to Nikunj Somia and Martin Dowds for their assistance in filming the videotape discussed in this paper, and Tony Lawrence for helping to recruit Ss in the second experiment.
} 


\title{
Recall of pseudo-psychic demonstrations
}

\begin{abstract}
This paper describes two experiments which investigate how believers in the paranormal (labelled 'Sheep') and disbelievers (labelled 'Goats') recall different aspects of pseudo-psychic demonstrations (i.e., conjuring tricks that can be misinterpreted as genuine psychic phenomena). In both experiments Ss were first shown a videotape containing pseudo-psychic trickery. They were then asked to rate the 'paranormal' content of the videotape and complete a set of recall questions. Ss were then told that the videotape contained magic tricks, and asked to complete a second set of recall questions. The recall questions contained information both 'important' and 'unimportant' to the method of the tricks. Overall, the results suggested that (i) Sheep displayed a slight tendency to rate the demonstrations as more 'paranormal' than Goats, (ii) initially Goats tended to recall significantly more 'important' information than Sheep and that, (iii) even when told that the videotape contained trickery, Goats tended to recall more 'important' information than Sheep (but only after Sheep had lost access to 'surface' memory for the videotape). Suggestions for improved methodology are given, along with proposals for future work in this area.
\end{abstract}


...the account of a trick by a person ignorant of the method used in its production will involve a misdescription of its fundamental conditions...so marked that no clue is afforded the student for the actual explanation.

Richard Hodgson, Proceedings of the Society for Psychical Research, 9, 360, 1894.

\section{INTRODUCTION}

In one of the first experimental studies of eyewitness testimony, Hodgson and Davey (1887) held fake seances for unsuspecting sitters, and requested each sitter to write a description of the seance after it had ended. Hodgson and Davey noted that sitters omitted many important events, and recalled others in an incorrect order. In a partial replication of this work, Besterman (1932) had sitters attend a fake seance and then answer questions relating to various phenomena that had occurred. Besterman reports that sitters had a tendency to underestimate the number of persons present in the seance room, to fail to report major disturbances that took place (e.g., the movement of the experimenter from the seance room), to fail to recall the conditions under which given phenomena took place, and to experience the illusory movements of objects. More recently, Jones \& Russell (1980) asked both believers in the paranormal (referred to as 'Sheep' ${ }^{2}$ ) and disbelievers (referred to as 'Goats') to observe a staged demonstration of extra-sensory perception (ESP). In one condition the demonstration was successful (i.e., ESP appeared to occur) whilst in the other it was not. Ss were then asked to recall the demonstration. Sheep who saw the unsuccessful demonstration distorted their memories of it and often stated that ESP had occurred. Goats correctly recalled the demonstration, even if it appeared to support the existence of ESP.

This work has important theoretical and pragmatic implications. Theoretically, these studies are of interest to psychologists concerned with eyewitness testimony, especially those researching human deception (e.g., Whaley, 1985; Lambert, 1987; Wiseman \& Morris, 1992). On a more pragmatic level, this work is of interest to individuals who are required to accurately observe, and recall, potential acts of deception. For example, parapsychologists investigating individuals claiming strong psychic ability have discovered that many of these claimants are fraudulent (see Kurtz, 1985; Hansen, 1990). In addition, both police and customs officers are often faced with the problem of detecting acts of concealment and deception. To be effective these investigators need to understand, and take account of, the ways in which their observation can be led astray by a competent trickster.

This paper describes two studies which further investigate the accuracy of testimony relating

\footnotetext{
${ }^{2}$ These are terms commonly used within parapsychology, and will be adopted for the remainder of this paper.
} 
to pseudo-psychic trickery (i.e., conjuring tricks that can be misinterpreted as genuine psychic phenomena). These studies concentrate on the effect that belief in the paranormal may have on the observation, and recall, of such demonstrations. There are several reasons to suspect that an individual's belief may play an important role in the observation and recall of such phenomena. First, previous research suggests that belief is an important source of bias when individuals observe certain types of events. For example, in a now classic study, Hastorf \& Cantril (1954) asked Ss to view, assess and recall a film of an important American football game. The recall of Ss supporting one team differed in many ways from the recall of Ss supporting the opposing team. Second, past work also indicates that individuals' belief in the paranormal correlates with performance on various measures of cognitive ability such as critical thinking ability and statistical reasoning (for an overview of this work, see French, 1992). Third, as mentioned above, the one study (Jones \& Russell, 1980) that has examined the influence of belief in the paranormal on the observation of pseudo-psychic phenomena reported interesting and significant results.

\section{EXPERIMENT ONE}

A videotape containing footage of a magician performing pseudo-psychic feats was shown to both Sheep and Goats. Ss were asked to rate the content of the videotape in terms of how 'paranormal' they felt it to be. It was proposed that both sets of observers would try to fit the content of the videotape to their preconceptions concerning the paranormal. It was hypothesized that Sheep would rate the demonstrations as significantly more paranormal than Goats.

Ss then answered two types of recall question, those that had previously been judged as either 'important' or 'unimportant' to the tricks' methods. Previous studies have found that (all else being equal) information that is relevant to Ss' expectancy is better recalled than information that is irrelevant (for a brief review of this 'importance effect' see Alba \& Hasher, 1983). It was assumed that Goats would view the demonstrations as magic tricks, and would therefore recall significantly more 'important' information than Sheep. Sheep and Goats were expected to recall the same amount of 'unimportant' information, as this was irrelevant to either of their perspectives. If this differential recall occurred, it could be interpreted in several ways. One possibility is that differences in prior belief primed the Ss to encode/store different types of information from the videotape. A second possibility is that the processes involved at the encoding/storage stages are quite similar, but that different 'retrieval sets' (i.e., attempting recall whilst believing the demonstrations to be either genuine psychic feats or magic tricks) may lead to the recall of different information. To tease apart these explanations Ss were next told that the videotape did not contain genuine paranormal phenomena, but magic tricks. Without seeing the videotape a second time, Ss were asked to complete a second set of recall 
questions (again, half of which were 'important', half 'unimportant'). If the hypothesised differential recall is due to differences in the encoding/storage stages of memory one would expect Sheep still to show a deficit for the recall of 'important' information. If this differential recall is due to differences in retrieval set one would expect Sheep and Goats to recall equivalent amounts of 'important' information. Previous research on this problem (for a brief review of the literature see Taylor \& Crocker, 1981) has found that encoding effects play a larger role in influencing recall than retrieval effects. Thus it was hypothesised that Goats would still recall significantly more 'important' information than Sheep in this later recall task. Again, differential recall for 'unimportant' information was not expected.

\section{Subjects}

Ss $(\mathrm{N}=37)$ were recruited from the undergraduate population of Aberdeen University via a poster advertising an experiment, and lecture, concerned with parapsychology.

\section{Materials}

\section{Videotape}

The videotape lasted six minutes and presented a magician (who performed the tricks), and an interviewer (who guided the magician from one trick to another). Both interviewer and magician were seated at a table throughout the videotape. The videotape contained two magic tricks. In the first demonstration (pseudo-ESP) the magician correctly divined cards taken from an ESP deck without looking at their faces. In the second demonstration (pseudoPK) a chosen fork bent and eventually broke whilst being gently stroked by the magician.

Both tricks were selected to fulfil several criteria. First, they did not require more than two individuals (i.e., one magician, one interviewer) for their performance. Second, neither of the tricks required either individual to leave the table. Third, the procedures that had to be carried out by magician and interviewer (e.g., choosing of cards, choosing of cutlery) were easily seen and understood. Fourth, the videotape had to hold the interest of the observer, and thus some parts of the tricks (e.g., the bending of the fork as it is rubbed by the magician) were visually dramatic.

The videotape was filmed from a single camera position (approximately seven foot from the performer) and was made in one take, such that there was no editing of the footage. The video camera did not cut away from the magician when he performed any type of trickery, and thus each of the tricks could be 'solved' (without extensive knowledge of conjuring) from the information contained on the videotape.

Belief in the Paranormal Questionnaire (BPQ) 
There are many measures available for measuring belief in the paranormal. However, most of them are not concerned with individuals' belief in the existence of genuine psychic claimants (the most relevant factor for this study), but measure much wider range of beliefs. For example, the Paranormal Belief Scale (Tobacyk \& Milford, 1983) measures belief in psychic ability, belief in traditional religious ideas and the existence of extraordinary life forms. For this reason, a 'Belief in the Paranormal Questionnaire' (BPQ) was devised for this experiment. It consisted of 6 questions. The questions dealt with the possible existence of individuals with different types of ESP (namely telepathy, clairvoyance and precognition) and PK (namely being able to paranormally influence a frequently occurring event such that the outcome of that event deviates away from chance, being able to apply a force to an object paranormally and altering the structure of an object paranormally). Ss responded to each question by ticking one of five responses indicating how probable they believed the phenomena to be. This questionnaire was scored by allotting a mark between 1 (strong agreement) and 5 (strong disagreement) to each of the six questions. This procedure meant that all Ss fell onto a continuum between 6 (strong Sheep) and 30 (strong Goat). Further details of this scale are given in the Appendix.

\section{Rating scale for demonstrations}

Ss were asked to give each of the two demonstrations a score between 1 ('definitely paranormal') and 7 ('definitely not paranormal').

\section{Recall questions}

For each of the two recall periods (i.e., both before and after Ss were told the videotape contained trickery) there were 4 recall questions per demonstration. Each recall question consisted of a statement about the videotape, followed by a five point scale on which the $\mathrm{S}$ indicated the degree to which (s)he felt the statement to be true or false. All questions had been previously independently rated by two magicians as either being 'important' or 'unimportant' to the tricks' methods (inter-rater reliability of 0.94). For example, in the 'fork bending/breaking' demonstration, the trick was achieved by the magician secretly placing (on camera) a pre-stressed fork onto the pile of cutlery. An 'important' statement would be 'The cutlery was touched by the psychic before the fork demonstration began', whilst an unimportant one would be 'At the end of the demonstration, the psychic returned any unbent cutlery to the pile'. All questions were counterbalanced, both in terms of the number of correct yes/no answers required, and across the First and Second Recall Periods. For each question, Ss recall was given a score between 0 and 4. If, for example, the answer to a recall question was 'True', Ss were awarded no marks for responding 'Definitely False', 1 mark for 'Probably False', 2 marks for 'Cannot Recall', 3 marks for 'Probably True' and 4 marks for 'Definitely True'. 


\section{Set-up}

Ss were group tested in a single session. The group was tested in a large lecture room in the Psychology Department of Aberdeen University. All Ss watched the videotape on a single 26 inch colour monitor. All Ss sat at separate tables, with the front row of Ss sitting approximately six feet away from the monitor.

\section{Procedure}

At the beginning of the session Ss completed the BPQ. The E carefully explained that the videotape the Ss were about to see contained footage of an individual who had approached the Koestler Chair of Parapsychology (at Edinburgh University) claiming to possess psychic powers. The E also explained that the videotape was taken as a first step in assessing the claimant, and that Ss should watch the videotape as closely as possible. The E ensured that all Ss had a clear view of the television screen. The videotape then was shown and Ss asked to rate the demonstrations in terms of how paranormal they felt them to be. Next, Ss were asked to complete the first set of recall questions (First Recall Period). The answers to these recall questions were then collected (to prevent Ss changing their answers after being told the videotape did not contain a psychic) and the E explained that the videotape did not contain a psychic, but a magician. Ss were then asked to complete the second set of recall questions (Second Recall Period).

\section{Results}

To provide a more detailed picture of the results, Ss scores for pseudo-ESP demonstrations were analyzed separately from those for the pseudo-PK demonstrations. For the former analyses Ss were grouped according to their responses on the first three questions on the $\mathrm{BPQ}$, whilst in the latter analysis they were grouped according to responses on the latter three questions. Ss were divided into two groups (Sheep and Goats) based on a median split. All of the analyses shown in the following tables are based on Mann-Whitney $U$ tests, using pvalues associated with a $\mathrm{z}$-score that has been corrected for ties.

\section{Pseudo-PK results}

The mean score on the last three questions of the BPQ (min score $=3$, max score $=15$, midpoint=9) for Sheep $(\mathrm{N}=19)$ was $6.1(\mathrm{sd}=2.0)$, and for Goats $(\mathrm{N}=18)$ was $11.3(\mathrm{sd}=2.0)$.

Table 1 contains the summary data for rating and recall scores in the First and Second Recall Periods. The hypothesis that Sheep would rate the demonstrations as significantly more 'paranormal' than Goats was confirmed. In the First Recall Period, the hypothesis that Goats would recall significantly more 'important' information than Sheep was also confirmed. There 
were no significant differences for the recall of 'unimportant' items. In the Second Recall Period the hypothesis that Goats would still recall significantly more 'important' information than Sheep was not confirmed. Again, there were no significant differences in recall for the 'unimportant' questions.

Insert Table 1 here

Pseudo-ESP results

The mean score on the first three questions of the BPQ ( $\min$ score $=3$, max score $=15$, midpoint=9) for Sheep $(\mathrm{N}=19)$ was $5.2(\mathrm{sd}=1.4)$, and for Goats $(\mathrm{N}=18)$ was $10.3(\mathrm{sd}=1.7)$.

Table 2 contains the summary data for rating and recall scores in the First and Second Recall Periods. Sheep rated the demonstrations as more paranormal than Goats, but this difference was not significant. In the First Recall Period, the hypothesis that Goats would recall significantly more 'important' information than Sheep was confirmed. There were no significant differences in recall for 'unimportant' items. In the Second Recall Period the hypothesis that Goats would recall significantly more 'important' information than Sheep was not confirmed. Again, there were no significant differences for the recall of 'unimportant' items.

Insert Table 2 here

\section{Discussion}

In the First Recall Period, Goats recalled significantly more 'important' information than Sheep for both the pseudo-PK and pseudo-ESP demonstrations. However, after being told that the videotape contained trickery, Sheep and Goats recalled equivalent amounts of 'important' information. This suggests that Sheep and Goats both encoded and stored the same amount of 'important' information from the videotape, but that retrieval set played a major role in determining whether this information was available at the time of recall. This finding is consistent with previous work reporting that shifts in perspective can alter the type of information recalled by Ss (see, e.g., Anderson \& Pichert, 1978). Some schema theorists have suggested that the strength of a memorial trace will (all else being equal) be directly related to the importance the observer attaches to information at the time of encoding (see, e.g., Lichtenstein \& Brewer, 1980). Information which is seen as important is encoded at a deeper level than that seen as unimportant. Following a shift in retrieval set, the observer 
reassigns the level of importance attached to this stored information. However, as relatively unimportant information is not strongly coded it may decay quite rapidly such that, after a certain time delay, the observer should not be able to recall it no matter how much importance is to be reassigned to it. This being the case, the shifts in recall described above should only be able occur for a limited time after initial encoding. The second experiment was designed to test this notion.

Methodologically, there is an alternative explanation of the above result. It is possible that Sheep/Goat differences are not stemming from recall per se., but from differences in 'response set'. Thus Goats may be looking out for questions that hint at trickery (e.g., questions involving objects, such as the fork, going out of sight on the videotape) and then answering those questions in a way compatible with the idea that trickery was afoot (e.g., the Goat might infer that the fork probably did go out of sight, thus allowing it to be secretly bent by the pseudo-psychic, regardless of whether these details can actually be recalled). If Goats were responding in this way, and Sheep were not, differential recall of 'important' items might be obtained. Although the idea of the 'response set' is important in its own right (in that it might give insight into how best to quiz observers who have experienced anomalous events), it was important that this factor was controlled for in the following experiment.

\section{EXPERIMENT TWO}

There were two main differences between the design of this experiment and the previous one. First, after watching the videotape, Ss were asked to spend a little time noting down any explanations they might have for the demonstrations that they had just seen. This was designed to provide necessary time for Ss to lose 'surface' memory of the videotape. Second, the recall periods now contained 'pseudo-important' questions that were constructed to control for the problem of 'response set'. 'Pseudo-important' questions were worded such that one might assume that they referred to aspects of the tricks' methods, but required answers opposite to those that would be given by Ss whose responses were based on this assumption (see the methods section below for details concerning the construction of these questions).

Several hypotheses were made. First, it was predicted that Sheep would rate the demonstrations as significantly more paranormal than Goats. In the First Recall Period it was predicted that Goats would recall significantly more 'important' items than Sheep. Sheep and Goats were expected to recall the same number of 'unimportant' items. If this differential recall was due to accurate remembering one would expect there to be no significant difference between Goats' and Sheep's recall on 'pseudo-important' questions. If however, the differential recall was due to the use of 'response sets' one would expect Goats to correctly recall significantly less 'pseudo-important' information than Sheep. It was 
hypothesised that the time delay between the First and Second Recall Periods would ensure that Sheep would lose access to 'important' information, and it was predicted that Goats would still recall significantly more 'important' items than Sheep in the Second Recall Period. Again, Sheep and Goats were not expected to show any differences for 'unimportant' information recalled. Finally, the role of 'response sets' in this Second Recall Period could be assessed via the use of 'pseudo-important' questions, as described above.

\section{Subjects}

Ss $(\mathrm{N}=33)$ were recruited from the University of London $(\mathrm{N}=15)$ and Edinburgh University $(\mathrm{N}=18)$, via posters advertising an experiment in parapsychology.

\section{Materials}

Videotape

The videotape contained footage of a magician performing four pseudo-psychic effects. Two of the effects consisted of pseudo-ESP and involved the magician divining the face of a concealed playing card. The other two demonstrations consisted of pseudo-PK. The first involved fake key bending, the second consisted of the bending/breaking of a fork. Although each of the examples of both pseudo-PK and -ESP appeared to be very similar (i.e., the divination of a chosen card and the paranormal influence on a metal object), different methods of trickery were employed for each trick. For example, in the first demonstration the magician 'forced' the interviewer to select a certain card, whereas in the second demonstration the magician gained access to the design drawn by the interviewer. Each demonstration was filmed so that the first demonstration could not be accounted for by the second explanation and vice versa.

BPQ and rating scales

The BPQ and rating scales remained the same as in the previous experiment. The ratings for the two pseudo-ESP demonstrations were summed to produce an overall rating, and the two pseudo-PK ratings were treated similarly.

\section{Recall questions}

For each of the two recall periods there were three questions per demonstration. The recall questions for the two pseudo-ESP demonstrations were identical, and those for the two pseudo-PK demonstrations were as similar as possible. Each of these sets of questions contained one item concerned with an event important to the particular trick's method (labelled 'important'), a second question concerned with an event unimportant to the trick's method, but important to the other trick in question (labelled 'pseudo-important') and finally, a third question concerned with an event unimportant to either tricks' method (labelled 
'unimportant'). For example, the 'fork bending/breaking' demonstration was achieved by the magician secretly placing (on camera) a pre-stressed fork onto the pile of cutlery. Thus an 'important' statement for this demonstration would be 'The cutlery was touched by the psychic before the fork demonstration began'. In contrast, the key bending demonstration was achieved by the magician secretly switching a straight key for one which had already been bent. This switch entailed the key going out of sight for a few moments. An 'important' question for the key bending demonstration was 'When passing the key from one hand to the other, it went out of sight on the videotape'. However, in the 'bending fork' demonstration the chosen fork was always in sight on the videotape and thus the pseudo-important question became 'When passing the fork from one hand to the other, it went out of sight on the videotape'. Likewise, during the 'key bending' demonstration the magician did not touch the keys before the demonstration, and thus the 'pseudo-important' question was 'The pile of keys was touched by the psychic before the key bending demonstration began'.

Recall questions were counter-balanced, and scored, as in the first experiment.

\section{Set-up}

Ss watched the videotape on a 26 inch colour monitor. All Ss sat at separate tables, with the front row of Ss sitting approximately six feet away from the monitor. Ss drawn from London University were group tested; those recruited from Edinburgh University were tested individually ${ }^{3}$.

\section{Procedure}

The procedure was almost identical to that described for the first experiment. The only difference was that Ss spent approximately five minutes noting down any explanations for the phenomena before completing the first set of recall questions.

\section{Results}

Pseudo-PK results

The mean score on the last three questions of the BPQ (min score $=3$, max score $=15$, midpoint=9) for Sheep $(\mathrm{N}=16)$ was $6.3(\mathrm{sd}=1.5)$, and for Goats $(\mathrm{N}=17)$ was $11.1(\mathrm{sd}=1.9)$.

Table 3 contains the summary data for all of the following analyses. The first hypothesis predicted that Sheep would rate the demonstrations as significantly more 'paranormal' than Goats. The difference was in the predicted direction, but not significant. In the First Recall Period, the hypothesis that Goats would recall significantly more 'important' information than

\footnotetext{
${ }^{3}$ Ss from London and Edinburgh University showed the same patterns and, for this reason, will be grouped together.
} 
Sheep was confirmed. Unexpectedly, the difference between Sheep and Goats recall of 'unimportant' information was relatively large, but not significant. There was no significant difference in Sheep/Goat performance for the recall of 'pseudo-important' questions. This suggests that the differential recall of 'important' information cannot be accounted for in terms of Sheep and Goats using differing 'response sets' toward the wording of the questions. In the Second Recall Period, the hypothesis that Goats would recall significantly more 'important' questions than Sheep was confirmed. There were no significant differences between Goats and Sheep, for the recall of 'unimportant' questions or 'pseudo-important' questions. Again, this suggests that the differential recall of 'important' information cannot be accounted for in terms of Sheep and Goats using differing 'response sets'.

Insert Table 3 here

Pseudo-ESP results

The mean score on the first three questions of the BPQ (min score $=3$, max score $=15$, midpoint=9) for Sheep $(\mathrm{N}=16)$ was $5.2(\mathrm{sd}=1.3)$, and for Goats $(\mathrm{N}=17)$ was $9.5(\mathrm{sd}=2.3)$.

Table 4 contains the summary data for all of the following analyses. It was predicted that Sheep would rate the demonstrations as significantly more 'paranormal' than Goats. Although the difference was in the predicted direction, it was not significant. In this First Recall Period, the hypothesis that Goats would correctly recall significantly more 'important' items than Sheep was not confirmed. There was no significant difference between the number of 'pseudo-important' questions correctly recalled by Goats and Sheep. Unexpectedly, Goats did recall significantly more 'unimportant' information than Sheep. In the Second Recall Period, the hypothesis that there would be a significant difference between the number of 'important' items correctly recalled by Goats and Sheep was confirmed. There were no significant differences between Goats and Sheep for the recall of either 'unimportant' or 'pseudoimportant' items.

\section{Insert Table 4 here}

\section{GENERAL DISCUSSION}

Several interesting findings have emerged from these studies.

First, Sheep had a slight tendency to rate the demonstrations as more paranormal than Goats. These differences were in the predicted direction but not significant in either the pseudo-ESP demonstration in Experiment One or both demonstrations in Experiment Two. The 
difference was only significant for the pseudo-PK demonstration in Experiment One.

Second, Goats tended to recall more 'important' but not 'unimportant' information than Sheep in the First Recall Period. This was true of both demonstrations in Experiment One and the pseudo-PK demonstrations in Experiment Two. These results suggest that Goats are better at recalling the important aspects of pseudo-psychic demonstrations. However, this finding was not replicated for the pseudo-ESP demonstrations in Experiment Two. Here, there was no difference between Sheep/Goats recall of 'important' information, but Goats did recall significantly more 'unimportant' information than Sheep. This unexpected finding may have been caused by these Goats being quite atypical, in that they displayed a rather low disbelief in the paranormal. For the pseudo-PK demonstrations the Sheep and Goat BPQ scores are consistent across the two experiments. In contrast, Goats in the pseudo-ESP condition of Experiment Two have a lower BPQ score (mean=9.5, sd=2.3) than Goats in the pseudo-ESP condition of Experiment One (mean=10.3, sd=1.7). This difference between the groups was tested with a Mann-Whitney $U$ test and proved significant ( $\mathrm{p}$ [corrected for ties, 1 tail] $=0.032$ ). Thus, in Experiment Two, Goats watching the pseudo-ESP demonstrations may have been less motivated to watch the videotape for trickery, thus leading to no difference in the recall of 'important' questions. It is harder to postulate why the significant difference in Goat/Sheep recall of 'unimportant' information might also have been caused by this 'low disbelief' Goat group, and this unexpected finding should be the subject of future research.

Third, the second experiment demonstrated that this differential recall was not accounted for by Sheep and Goats employing different 'response sets'.

Fourth, differential recall for 'important' and 'unimportant' information in the Second Recall Period occurred only when a problem solving task had been inserted between the observation of the videotape and the recall periods. This supports the notion that there may be a window of time in which Sheep, when told the videotape contains trickery, can still gain access to a 'surface' memory trace, and thus still recall relatively large amounts of 'important' information. This result could also be the subject of future research. Such research could vary the time delay, between viewing of the video and first recall period, to find out when differential recall starts to be obtained. Alternatively, such research could examine the types of task that, when placed between observation of the videotape and initial recall, either act to disrupt, or enhance, recall performance.

The differential rating and recall described above could be interpreted in several ways. For example, it is possible that when observing a psychic claimant, Goats are superior to Sheep, 
regardless of the validity of the claimant (e.g., Goats are more likely to avoid both false positive and false negative errors). It is also possible that Goats' disbelief in the paranormal caused them to correctly observe the claimant as a pseudo-psychic, without necessarily considering the actual data. Future research should aim to examine these issues, perhaps by presenting Ss with a videotape of a claimant performing phenomena that could not be explained by sleight-of-hand (this videotape could perhaps be constructed using careful camera trickery). It may be that Goats would rate the videotape as containing a genuine psychic (or at least be puzzled by his/her apparent abilities). This result, when combined with the results of the studies described in this paper, would indicate that, when assessing psychic claimants, Goats can go against their natural bias, whereas Sheep cannot. Alternatively, the results from this hypothetical study may reveal that Goats erroneously rate the claimant as a pseudo-psychic. Such a finding would indicate that accurate attribution of psychic ability depends, in part, on observers' belief in the paranormal conforming to the validity of a claimant's actual psychic ability.

Future experimentation in this area should include methodological improvements. For example, these two experiments contained no measures to ensure that Ss believed the experimenter when he stated that the videotape contained trickery. This check is necessary given that Singer \& Benassi (1981) found that many Ss simply didn't believe an experimenter who stated that the individual who had just performed some pseudo-psychic tricks was, in reality, a magician. In addition, the studies provided no control over which Ss sat close to the monitor used to display the videotape. It could be argued that Goats were simply more enthusiastic observers, sat closer to the television and therefore observed more 'important' information than Sheep. Although this explanation would fail to account for why, in the first experiment, Sheep could later recall this 'important' information, this possibility should be controlled for in future research. Finally, some of the results from the pseudo-ESP demonstration in Experiment Two were not consistent with the overall findings. Future research could further explore why this was the case.

In short, these studies have developed a method that provides researchers with a useful way of accurately assessing various issues involved in the recall of complex material. This method could be used to carry out some of the future work proposed above. In addition, this method could be used to examine the observation, and recall, of other types of ostensible psychic events (e.g., psychic surgery) and acts of deception (e.g., pickpocketing, con games) by different types of observers (e.g., parapsychologists who have observed several ostensibly psychic demonstrations or magicians). Such studies will lead to further insight into how different schemata affect the observation/recall of both pseudo-psychic trickery and other acts of deception. 


\section{REFERENCES}

Alba, J.W. \& Hasher, L. (1983). Is memory schematic? Psychological Bulletin, 93, 203-223.

Anderson, R.C., \& Pichert, J.W. (1978). Recall of previously unrecallable information following a shift in perspective. Journal of Verbal Learning and Verbal Behaviour, 17, 1-12.

Besterman, T. (1932). The psychology of testimony in relation to paraphysical phenomena: Report of an experiment. Proceedings of the Society For Psychical Research, 40, 363-387.

French, C.C. (1992). Factors underlying belief in the paranormal: Do sheep and goats think differently? The Psychologist, 5, 295-299.

Hansen, G.P. (1990). Deception by subjects in psi research. The Journal of the American Society for Psychical Research, 84, 25-80.

Hastorf, A.H., \& Cantril, H. (1954). They saw a game: A case study. Journal of Abnormal and Social Psychology, 49, 129-134.

Hodgson, R. \& Davey, S.J. (1887). The possibilities of mal-observation and lapse of memory from a practical point of view. Proceedings of the Society For Psychical Research, 4 , 381-495.

Jones, W.H. \& Russell, D. (1980). The selective processing of belief disconfirming information. European Journal of Social Psychology, 10, 309-312.

Kurtz, P. (1985). Spiritualists, mediums and psychics: Some evidence of fraud. In P. Kurtz (Ed.). A Skeptics Handbook of Parapsychology. 177-223. Buffalo, NY: Prometheus Books.

Lambert, D. R. (1987). A cognitive model for the exposition of human deception and counterdeception. San Diego, CA: Naval Oceans Systems Center. Technical Report 1079.

Lichtenstein, E.H. \& Brewer, W.F. (1980). Memory for goal directed events. Cognitive Psychology, 12, 412-445.

Singer, B. \& Benassi, V.A. (1981). Occult beliefs. American Scientist, 69, 49-55.

Taylor, S.E. \& Crocker, J. (1981). Schematic bases of social information processing. In E.T. Higgins, C.P. Herman and M.P. Zanna (Eds.), Social Cognition: The Ontario symposium on personality and social personality. Hillsdale, N.J.: Erlbaum, pp. 89-133.

Tobacyk, J.J. \& Milford, G. (1983). Belief in paranormal phenomena: assessment instrument development and implications for personality functioning. Journal of Personality and Social Psychology, 44, 1029-1037.

Whaley, B. (1985). Toward a general theory of deception. Journal of Strategic Studies, 5(1), 178-192.

Wiseman, R. \& Morris, R.L. (1992). Law enforcement and the psychology of deception. Police Requirements Support Unit Bulletin, 42, 41-43. 
TABLES

\begin{tabular}{||l|l|l|l|l|l||}
\hline & & \multicolumn{2}{|l|}{ First Recall Period } & Second Recall Period \\
\hline & $\begin{array}{l}\text { Rating } \\
\min =1 \\
\max =7\end{array}$ & $\begin{array}{l}\text { Import. } \\
\text { items } \\
\min =0 \\
\max =8\end{array}$ & $\begin{array}{l}\text { Unimport. } \\
\text { items } \\
\min =0 \\
\max =8\end{array}$ & $\begin{array}{l}\text { Import. } \\
\text { items } \\
\min =0 \\
\max =8\end{array}$ & $\begin{array}{l}\text { Unimport. } \\
\text { items } \\
\min =0 \\
\max =8\end{array}$ \\
\hline Sheep & 2.94 & 3.89 & 3.94 & 5.00 & 4.47 \\
$\mathrm{~N}=19$ & $(1.66)$ & $(2.72)$ & $(1.83)$ & $(1.69)$ & $(2.00)$ \\
\hline Goats & 4.61 & 5.26 & 4.57 & 5.15 & 4.63 \\
$\mathrm{~N}=18$ & $(1.61)$ & $(2.10)$ & $(1.86)$ & $(1.83)$ & $(1.77)$ \\
\hline p-values & $.001^{*}$ & $.05^{*}$ & .46 & .31 & .41 \\
& $(1$ tail $)$ & $(1$ tail $)$ & $(2$ tail $)$ & $(1$ tail $)$ & $(2$ tail $)$ \\
\hline
\end{tabular}

Table 1: Means, standard deviations (in brackets) and p-values for rating/recall scores of pseudo-PK demonstrations in Experiment 1. ' ${ }^{* 1}$ denotes $\mathbf{p}<0.05$.

\begin{tabular}{|c|c|c|c|c|c|}
\hline & & \multicolumn{2}{|c|}{ First Recall Period } & \multicolumn{2}{|c|}{ Second Recall Period } \\
\hline & $\begin{array}{l}\text { Rating } \\
\min =1 \\
\max =7\end{array}$ & $\begin{array}{l}\text { Import. } \\
\text { items } \\
\min =0 \\
\max =8\end{array}$ & $\begin{array}{l}\text { Unimport } \\
\text { items } \\
\min =0 \\
\max =8\end{array}$ & $\begin{array}{l}\text { Import. } \\
\text { items } \\
\min =0 \\
\max =8\end{array}$ & $\begin{array}{l}\text { Unimport } \\
\text { items } \\
\min =0 \\
\max =8\end{array}$ \\
\hline $\begin{array}{l}\text { Sheep } \\
\mathrm{N}=19\end{array}$ & $\begin{array}{l}4.32 \\
(1.56) \\
\end{array}$ & $\begin{array}{l}5.10 \\
(1.73) \\
\end{array}$ & $\begin{array}{l}5.05 \\
(2.29) \\
\end{array}$ & $\begin{array}{l}6.00 \\
(1.78)\end{array}$ & $\begin{array}{l}4.83 \\
(2.53) \\
\end{array}$ \\
\hline $\begin{array}{l}\text { Goats } \\
\mathrm{N}=18\end{array}$ & $\begin{array}{l}4.83 \\
(1.46) \\
\end{array}$ & $\begin{array}{l}5.94 \\
(1.62) \\
\end{array}$ & $\begin{array}{l}5.50 \\
(1.50) \\
\end{array}$ & $\begin{array}{l}5.89 \\
(1.87) \\
\end{array}$ & $\begin{array}{l}4.66 \\
(1.94) \\
\end{array}$ \\
\hline p-values & $\begin{array}{l}.20 \\
(1 \text { tail })\end{array}$ & $\begin{array}{l}.02 * \\
(1 \text { tail })\end{array}$ & $\begin{array}{l}.90 \\
(2 \text { tail })\end{array}$ & $\begin{array}{l}.40 \\
(1 \text { tail })\end{array}$ & $\begin{array}{l}.52 \\
\text { (2 tail) }\end{array}$ \\
\hline
\end{tabular}

Table 2: Means, standard deviations (in brackets) and p-values for rating/recall scores of pseudo-ESP demonstrations in Experiment 1. ' $*$ ' denotes $\mathbf{p}<0.05$. 


\begin{tabular}{|c|c|c|c|c|c|c|c|}
\hline & & First Re & Il Period & & Second & call Peri & \\
\hline & $\begin{array}{l}\text { Rating } \\
\min =2 \\
\max =14\end{array}$ & $\begin{array}{l}\text { Import. } \\
\text { items } \\
\min =0 \\
\max =8\end{array}$ & $\begin{array}{l}\text { Unimpt. } \\
\text { items } \\
\min =0 \\
\max =8\end{array}$ & $\begin{array}{l}\text { Pseudo- } \\
\text { impt. } \\
\text { items } \\
\min =0 \\
\max =8\end{array}$ & $\begin{array}{l}\text { Import. } \\
\text { items } \\
\min =0 \\
\max =8\end{array}$ & $\begin{array}{l}\text { Unimpt. } \\
\text { items } \\
\min =0 \\
\max =8\end{array}$ & $\begin{array}{l}\text { Pseudo- } \\
\text { impt. } \\
\text { items } \\
\min =0 \\
\max =8\end{array}$ \\
\hline $\begin{array}{l}\text { Shee } \\
\text { p } \\
\mathrm{N}=16\end{array}$ & $\begin{array}{l}8.56 \\
(3.48)\end{array}$ & $\begin{array}{l}5.31 \\
(2.02)\end{array}$ & $\begin{array}{l}4.44 \\
(2.25)\end{array}$ & $\begin{array}{l}4.38 \\
(2.09)\end{array}$ & $\begin{array}{l}5.66 \\
(1.63)\end{array}$ & $\begin{array}{l}3.93 \\
(2.54)\end{array}$ & $\begin{array}{l}3.80 \\
(2.33)\end{array}$ \\
\hline $\begin{array}{l}\text { Goat } \\
\text { s } \\
\mathrm{N}=17\end{array}$ & $\begin{array}{l}9.94 \\
(3.32)\end{array}$ & $\begin{array}{l}6.52 \\
(1.46)\end{array}$ & $\begin{array}{l}5.94 \\
(2.16)\end{array}$ & $\begin{array}{l}4.11 \\
(2.15)\end{array}$ & $\begin{array}{l}6.82 \\
(1.33)\end{array}$ & $\begin{array}{l}4.17 \\
(2.40)\end{array}$ & $\begin{array}{l}3.29 \\
(2.08)\end{array}$ \\
\hline $\begin{array}{l}\mathrm{p}- \\
\text { value }\end{array}$ & $\begin{array}{l}.12 \\
(1 \text { tail })\end{array}$ & $\begin{array}{l}.04 * \\
\text { (1 tail) }\end{array}$ & $\begin{array}{l}.06 \\
\text { (2 tail) }\end{array}$ & $\begin{array}{l}.75 \\
(2 \text { tail) }\end{array}$ & $\begin{array}{l}.02 * \\
\text { (1 tail) }\end{array}$ & $\begin{array}{l}.90 \\
(2 \text { tail) }\end{array}$ & $\begin{array}{l}.60 \\
(2 \text { tail })\end{array}$ \\
\hline
\end{tabular}

Table 3: Means, standard deviations (in brackets) and p-values for rating/recall scores of pseudo-PK demonstrations in Experiment 2. '*' denotes $\mathbf{p}<0.05$.

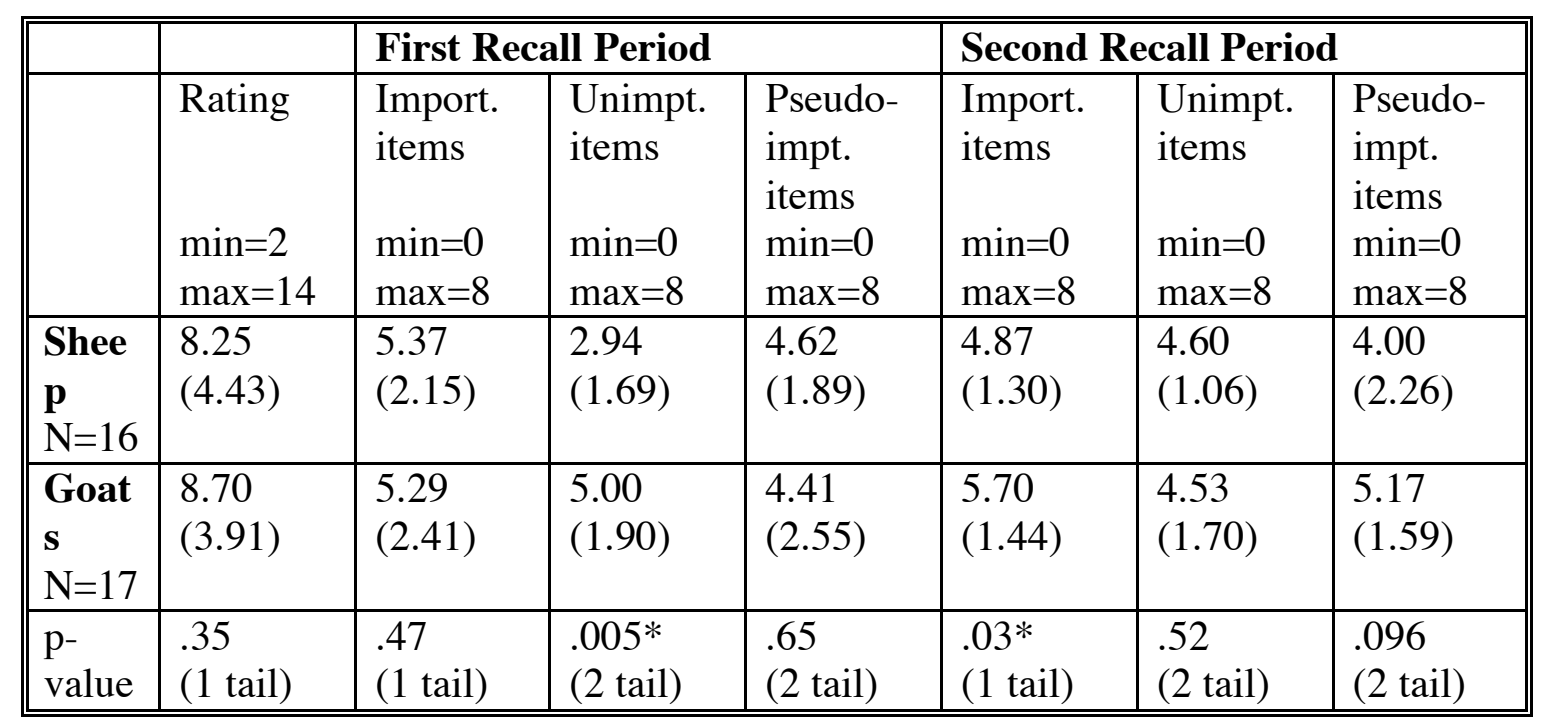

Table 4: Means, standard deviations (in brackets) and p-values for rating/recall scores of pseudo-ESP demonstrations in Experiment 2. ${ }^{*} *$ ' denotes $\mathbf{p}<0.05$. 


\section{APPENDIX}

Belief in the Paranormal Questionnaire (BPQ)

The six questions of the BPQ scale are reproduced below:

1) Do you think that some people are able to gain, by paranormal means, access to information being thought of by others?

2) Do you think that some people are able to gain, by paranormal means, access to information that nobody else is aware of at the time (e.g. the order of a shuffled deck of cards)?

3) Do you think that some people can, by paranormal means, know what is going to happen in the future?

4) Do you think that some people can influence a frequently occurring event (e.g. a number of rolls of dice) such that the outcome of that event deviates away from chance (e.g. the dice show more or less 'sixes' than would be predicted by chance alone)?

5) Do you think that some people can, just by mental effort, apply a noticeable force to an object?

6) Do you think that some people can, just by mental effort, alter the physical characteristics of the material from which an object is made? 